\title{
Miscanthus Clones Display Large Variation in Floral Biology and Different Environmental Sensitivities Useful for Breeding
}

\author{
Stéphanie Arnoult • Marie-Christine Quillet • \\ Maryse Brancourt-Hulmel
}

Published online: 26 October 2013

(C) The Author(s) 2013. This article is published with open access at Springerlink.com

\begin{abstract}
A wider range of Miscanthus varieties is required to develop Miscanthus clones that are suitable for bioenergy production. For this reason, breeding programs need to be initiated using knowledge regarding the genetic influence on floral biological traits. The objective of the present study was to characterize the genotypic variation in flowering and panicle architecture traits in Miscanthus by studying (i) the clone effect on these traits and (ii) the clone sensitivity to environmental conditions. The flowering traits characterized were date of panicle emergence, date of flowering onset, and interval between these two traits. The panicle architecture traits characterized were total panicle length, longest panicle raceme size, raceme number per panicle, floral density, and total flower number per panicle. Eight clones were studied in a greenhouse under four environmental conditions including two day lengths (an 8-h short day length and a natural day length) and two temperature treatments (warm and cool). Miscanthus clones showed large differences in flowering and panicle architecture traits. Moreover, day length appeared to be the most important environmental factor creating differential clone sensitivities for the panicle emergence and the onset of flowering in contrast to temperature factor for the total flower number per panicle. In addition, the behavior of the clone Sacc was in contrast with that of the other clones for most of the traits studied. This knowledge will be useful to
\end{abstract}

S. Arnoult $(\bowtie) \cdot M$. Brancourt-Hulmel

INRA, UMR1281 Stress Abiotiques et Différenciation des Végétaux

cultivés, 2 Chaussée Brunehaut, Estrées-Mons, BP 50136,

80203 Péronne Cedex, France

e-mail: Stephanie.Arnoult@mons.inra.fr

M.-C. Quillet

Université des Sciences et Technologies de Lille 1, UMR1281 Stress

Abiotiques et Différenciation des Végétaux cultivés,

59655 Villeneuve d'Ascq, France optimize the synchronization of flowering between Miscanthus clones for more successful breeding programs.

Keywords Miscanthus clones · Flowering traits · Panicle architecture traits $\cdot$ Environmental conditions

$\begin{array}{ll}\text { Abbreviations } \\ \text { C } & \text { Cool } \\ \text { CV } & \text { Coefficient of variation } \\ \text { dd } & \text { Degree days } \\ \text { LSMEANS } & \text { Least-squares means } \\ \text { ND } & \text { Natural day length } \\ \text { OF } & \text { Onset of flowering } \\ \text { PE } & \text { Panicle emergence } \\ \text { SD } & \text { Short day length } \\ \text { W } & \text { Warm }\end{array}$

Climate change, declining supplies of fossil fuels, and the development of renewable energy sources are major concerns worldwide. Plant biomass can be used to produce renewable energy, and the biomass from the $\mathrm{C} 4$ perennial rhizomatous grass Miscanthus appears to be a good candidate for bioenergy production [1] due to its high productivity [2] and favorable energy balance [3]. New Miscanthus varieties are therefore needed to promote the current increase in cultivated areas.

The Miscanthus genus sensu stricto contains approximately 11 to 12 species [4] originating from a broad geographical area, including tropical and subtropical regions [5]. Miscanthus belongs to the tribe of Andropogoneae and the subtribe of Saccharineae. Miscanthus is related to maize and sorghum, which belong to the tribe of Andropogoneae, and is closely related to sugarcane, which also belongs to the subtribe of Saccharineae. Many studies have investigated the importance of flowering time management for breeding 
programs, particularly in sugarcane [6-17]. In particular, Gosnell [18] and Berding et al. [10-13] showed that genotype variability in panicle number and flowering stem (stalk) number in sugarcane could be useful for the synchronization of flowering, which could increase the success rate for crossings in breeding programs.

Differences have also been observed in flowering time in the Miscanthus genus [4, 19-23]. Clifton-Brown et al. [4, 20], Jensen et al. [21, 22], and Gauder et al. [23] measured differences in the flowering time between and within Miscanthus sinensis, Miscanthus sacchariflorus, and interspecific hybrids of Miscanthus. This suggested a genetic variability for this trait in the Miscanthus genus. In addition to flowering time management, panicle architecture can also be investigated for the breeding of Miscanthus. However, the relationship between genetic variability and these two traits has never been extensively investigated.

Environmental effects on the management of flowering and panicle architecture traits have to be considered. In sugarcane, Nuss [24] showed that day-length treatments could be used to synchronize crossings between early- and late-flowering sugarcane varieties, which have no naturally synchronous flowering times. Moreover, Machado et al. [25], Berding et al. [9-11, 13], and Rizk et al. [26] showed significant interactions between genotype and environment in sugarcane. In Miscanthus, only a few publications have reported such environmental effects; Jensen et al. [21, 22] demonstrated an environmental effect on Miscanthus flowering time and determined that flowering induction in Miscanthus sacchariflorus was a short-day response. However, no study on Miscanthus reported the effect of the genotype $\times$ environment interaction on flowering and panicle architecture traits although many authors studied this effect on biomass traits (see for instance Clifton-Brown et al. [20] and Jezowski et al. [27]).

As breeding programs require knowledge of the genetic variability related to the traits of interest [28], the genetic variations of Miscanthus need to be precisely characterized. Therefore, clonal variability on the flowering and panicle architecture traits must be further studied to enable the synchronization of flowering and increase the crossing success in Miscanthus breeding. The aim of the present study was to characterize the clonal effect, corresponding to the variability among Miscanthus clones, in flowering and panicle architecture. We tested two hypotheses. Firstly, we predicted that there would be a clonal variability in the flowering and panicle traits as the Miscanthus genus comprises several species. We also predicted that the sensitivity of the clones to the environmental conditions was different as the Miscanthus species originated from a broad geographical area.

We firstly explored the flowering and panicle architecture variability among eight clones, seven clones belonging to the M. sinensis species and one clone belonging to the $M$. sacchariflorus species. Secondly, we focused on the sensitivity of these clones to environmental conditions by subjecting the eight clones to four environmental conditions, which combined two day-length treatments and two temperature treatments.

The observed clonal variability in Miscanthus flowering and panicle architecture traits and the environmental sensitivities of the clones will increase the knowledge regarding flowering and panicle architecture traits, which could be useful to optimize the synchronization of flowering between Miscanthus clones for more successful crossings.

\section{Materials and Methods}

The clone and the environmental effects on flowering and panicle architecture traits were tested in greenhouses during two successive years, 2007 and 2008. In 2007, the rhizomes were planted on the 10th of April. In 2008, the rhizomes were planted in the same greenhouse on the 12th of March.

\section{Plant Material}

Eight Miscanthus clones were used in this study that came from two European nurseries (one in France and one in Belgium). Seven belonged to the $M$. sinensis species: $M$. sinensis August Feder (Aug), M. sinensis Ferner Osten (Fern), M. sinensis Flamingo (Flam), M. sinensis Goliath (Gol), M. sinensis Malepartus (Male), M. sinensis Rotsilber (Rot), and M. sinensis Yaku Jima (Yaku); and one belonged to the M. sacchariflorus species: M. sacchariflorus (Sacc) (Table 1). The biomass yield of this selection of clones was provided in Zub et al. [29]. In field conditions, without any inputs, the biomass yields of these clones varied from $1.4 \mathrm{t}$ to $15.6 \mathrm{t}$ /ha at winter harvest during the third year of the crop.

For each clone, 20 rhizomes were prepared as replicates for crop establishment. Each rhizome was approximately $5-\mathrm{cm}$ long and had at least three visible buds to ensure a satisfactory emergence rate [30]. The rhizomes were planted at approximately a $10-\mathrm{cm}$ depth in 5 -liter plastic pots containing universal potting compost and were maintained in a greenhouse. In 2008, the twenty rhizomes were prepared from those of the plants at the end of the first experiment, performed in 2007, and were divided in an identical manner as for the first experiment.

\section{Environmental Conditions}

The measure of the environmental sensitivity of each clone was investigated through the test of each clone in four environmental conditions which combined two day-length treatments (a natural day length and a short day length) and two temperatures (warm and cool): 
Table 1 Description of the eight Miscanthus clones studied, including species, clone name, ploidy level, origin, and traits observed for each clone

\begin{tabular}{lllllll}
\hline Species & Name & Code & $\begin{array}{l}\text { Ploidy } \\
\text { level }\end{array}$ & Origin & $\begin{array}{c}\text { Traits related to } \\
\text { flowering }\end{array}$ & $\begin{array}{c}\text { Traits related to panicle } \\
\text { architecture }\end{array}$ \\
\hline M. sacchariflorus & & Sacc & $2 \mathrm{x}$ & France, Nursery Chombart & $\mathrm{X}$ & $\mathrm{X}$ \\
M. sinensis & 'August Feder' & Aug & $2 \mathrm{x}$ & France, Nursery Chombart & & $\mathrm{X}$ \\
M. sinensis & 'Ferner Osten' & Fern & $2 \mathrm{x}$ & Belgium, Nursery Bruckeveld & $\mathrm{X}$ \\
M. sinensis & 'Flamingo' & Flam & $2 \mathrm{x}$ & France, Nursery Chombart & $\mathrm{X}$ & $\mathrm{X}$ \\
M. sinensis & 'Goliath' & Gol & $4 \mathrm{x}$ & France, Nursery Chombart & $\mathrm{X}$ \\
M. sinensis & 'Malepartus' & Male & $2 \mathrm{x}$ & France, Nursery Chombart & $\mathrm{X}$ & $\mathrm{X}$ \\
M. sinensis & 'Rotsilber' & Rot & $2 \mathrm{x}$ & France, Nursery Chombart & & $\mathrm{X}$ \\
M. sinensis & 'Yaku Jima' & Yaku & $2 \mathrm{x}$ & Belgium, Nursery Bruckeveld & $\mathrm{X}$ & \\
\hline
\end{tabular}

${ }^{a}$ It included date of panicle emergence, date of onset of flowering, and interval between panicle emergence and onset of flowering

${ }^{b}$ It corresponded to total panicle length, size of the longest panicle raceme, number of racemes per panicle, floral density, and total number of flowers per panicle

- Environmental condition 1: short day length (SD) and cool temperature $(\mathrm{C})$;

- Environmental condition 2: short day length (SD) and warm temperature $(\mathrm{W})$;

- Environmental condition 3: natural day length (ND) and cool temperature (C);

- Environmental condition 4: natural day length (ND) and warm temperature $(\mathrm{W})$.

Due to space constraints imposed by the size of the greenhouse, environmental conditions 1 and 3 were performed in 2008 while environmental conditions 2 and 4 were performed in 2007. Details on all environmental conditions are shown in Table 2. Additionally, evolution of natural day length during 2007 and 2008 was detailed in Fig. 1.

For each environmental condition, day length treatments (a natural day length and a short day length) were applied just after the plants sent out their flag leaf, which was the first observable indication that floral transition had occurred [22]. The date of flag leaf emergence was defined as the day when the collar of the flag leaf became visible. As flag leaf emergence varied according to Miscanthus clones [22], the plants of each clone studied were placed under day length treatments as a function of the date of their flag leaf emergence. An automatic roller blind was used for $5 \mathrm{~h}$ each day before dusk to generate the 8-h short-day treatment.

For all of the four environmental conditions tested, the plants were grown under ambient light conditions and irrigated when required to maintain water stress-free conditions. A cooling system maintained the relative air humidity at $50 \pm 15 \%$. Air temperature and relative air humidity were monitored using sensors (Pt100 Class A Temperature Sensor and Resistive Humidity Sensor, respectively, ARIA, France) placed in a ventilation shelter $1.4 \mathrm{~m}$ above the ground.

For each environmental condition, the clones were grown according to a complete randomized design and 10 plants per clone were used as replicates.

Table 2 Description of the four environmental conditions tested

\begin{tabular}{lllll}
\hline Environmental condition & Code & Day length & Air temperature & $\begin{array}{c}\text { Number of degree days } \\
\text { per day (average })\end{array}$ \\
\hline Environmental condition 1 & SD-C & Short days $(8 \mathrm{~h})$ & $\begin{array}{c}\text { Cool temperature } \\
\left(24 / 22 \pm 2{ }^{\circ} \mathrm{C} \text { until flag leaf emergence }\right. \\
\left.\text { and } 22 / 20 \pm 2{ }^{\circ} \mathrm{C} \text { after flag leaf stage }\right) \\
\text { Warm temperature } \\
\left(28 / 22 \pm 2{ }^{\circ} \mathrm{C} \text { until flag leaf emergence }\right. \\
\left.\text { and } 24 / 22 \pm 2{ }^{\circ} \mathrm{C} \text { after flag leaf stage }\right)\end{array}$ \\
Environmental condition 2 & SD-W & Short days $(8 \mathrm{~h})$ & $\begin{array}{c}11.3 \\
\text { Cool temperature } \\
\left(24 / 22 \pm 2{ }^{\circ} \mathrm{C} \text { until flag leaf emergence }\right. \\
\left.\text { and } 22 / 20 \pm 2{ }^{\circ} \mathrm{C} \text { after flag leaf stage }\right)\end{array}$ \\
Environmental condition 3 & ND-C & Natural day length $(12 \mathrm{~h} \mathrm{52)}$ & $\begin{array}{c}\text { Warm temperature } \\
\left(28 / 22 \pm 2{ }^{\circ} \mathrm{C} \text { until flag leaf emergence }\right. \\
\left.\text { and } 24 / 22 \pm 2{ }^{\circ} \mathrm{C} \text { after the flag leaf stage }\right)\end{array}$ \\
\hline
\end{tabular}

Environmental conditions 2 and 4 were performed in 2007; environmental conditions 1 and 3 were performed in 2008 


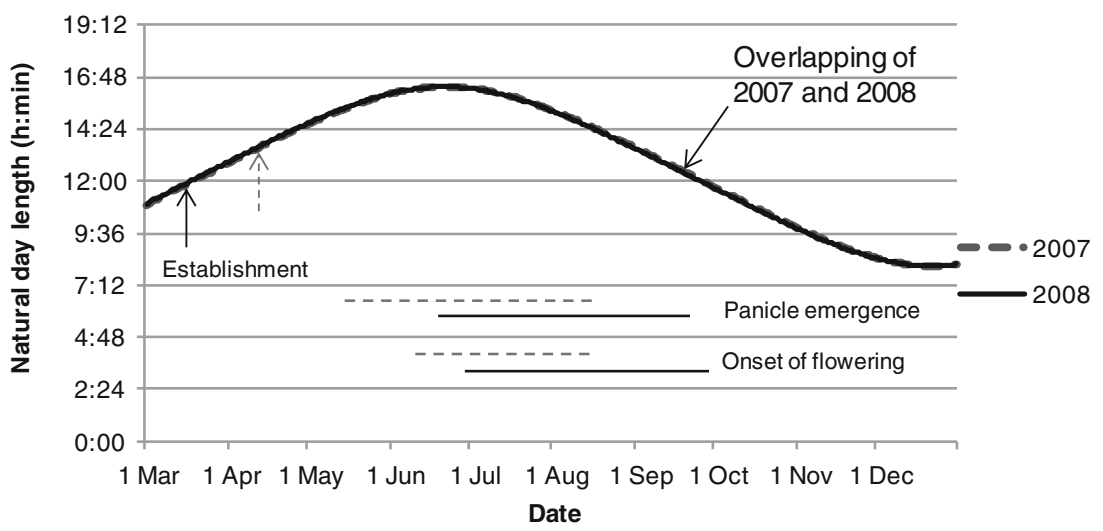

Fig. 1 Evolution of natural day length during 2007 and 2008. A total overlapping was observed between the two years. Arrows corresponded to the dates of rhizomes establishment in greenhouse during 2007 (dottedline arrow) and 2008 (continuous-line arrow). Horizontal lines corresponded to the duration of observations related to flowering traits (panicle emergence and onset of flowering) during 2007 (dotted lines) and 2008 (continuous lines). The observations of panicle architecture traits began the $16^{\text {th }}$ of October for both years

Statistical Analysis

Analyses of variance (ANOVA) were all performed with the SAS Software System [31] using the GLM procedure.

ANOVA was performed to investigate the effects of clones, and clone $\times$ environmental conditions interactions on all of the observed variables. The following model was used (type III sum of squares):

$Y_{i j k}=\mu+\alpha_{i}+\beta_{j}+\alpha \beta_{i j}+\varepsilon_{i j k}$,

where $\mu$ is the general mean of a given variable $Y$ for environmental condition $i$, clone $j$, and replicate $k$;

$\alpha_{i}$ is the main effect of the environmental condition;

$\beta_{j}$ is the main effect of the clone;

$\alpha \beta_{i j}$ is the interaction between the environmental condition and the clone;

and $\varepsilon_{i j k}$ corresponds to the residual error of the model.

All terms were considered to be fixed effects.

Due to missing values, a type III sum of squares was used to analyze the treatment effects on the flowering and panicle architecture traits. The least-squares means (LSMEANS), corresponding to adjusted means for unbalanced designs, were calculated. Bonferroni $t$ tests of differences between the LSMEANS for clone effect and interaction effect were performed (adapted to unbalanced designs). The interpretation was focused on the effect of the clone and the interaction between the environmental condition and the clone effect: the environmental condition effect was not interpreted as there was no replication for each environmental condition tested.

Three $t$ tests were performed on all of the observed variables with the SAS Software System [31] using the T TEST procedure. These $t$ tests were performed for each clone studied separately to identify which of the two environmental factors (temperature or day length) was responsible for the 
differential sensitivity of the clones: the first $t$ test compared the two temperatures, cool vs. warm (environmental conditions 1 and 3 vs. environmental conditions 2 and 4, respectively) while the second $t$ test compared the two day lengths, short days vs. natural day length (environmental conditions 1 and 2 vs. environmental conditions 3 and 4, respectively). Finally, a third $t$ test corresponded to the interaction between day length and temperature (environmental conditions 1 and 4 vs. environmental conditions 2 and 3, respectively). The $t$ test values were obtained using the Cochran method adapted to unequal variances between two samples.

\section{Results}

The coefficients of variation for the flowering and panicle architecture traits observed during this study were high, with the exceptions of the date of panicle emergence and the date of flowering onset, which showed lower coefficients of variation (Table 3). The ANOVA explained from 46 to $85 \%$ of the overall variation observed. Despite this low precision and the share of variability explained by the model, significant effects were detected by the ANOVA.

The Variability in Flowering and Panicle Architecture Traits is Mainly Due to the Clone

The main effect of clone was significant for all flowering and panicle architecture traits. This clone effect was also higher than the effect of clone $\times$ environmental condition interaction: the $F$ values for clone were always at least three times greater than the $F$ values for clone $\times$ environmental condition interaction (Table 3).

Among the clones studied, differences of $267 \mathrm{dd}(18 \%$ of the mean) and $257 \mathrm{dd}$ (16\% of the mean) were recorded for panicle emergence and the onset of flowering, respectively. Sacc was the earliest flowering clone, with values of $1354 \mathrm{dd}$ and $1425 \mathrm{dd}$ for panicle emergence and the onset of flowering, respectively. Yaku was the latest flowering clone, with 1621 $\mathrm{dd}$ and $1682 \mathrm{dd}$ recorded for panicle emergence and the onset of flowering, respectively. For these two traits, Flam and Male appeared to be in a middle position (Fig. 2).

For the interval between the PE and the OF, a difference of $31 \mathrm{dd}$ (63\% of the mean) was recorded among the clones studied. Male and Sacc presented the lowest intervals, with values of 36 and $41 \mathrm{dd}$, respectively. The greatest interval was recorded for Yaku, with a value of $67 \mathrm{dd}$. Flam appeared to be in a middle position for this trait (Fig. 2).

For total panicle length, a variability of $220 \mathrm{~cm}$ ( $89 \%$ of the mean) was observed. Male and Gol presented the highest lengths, with measurements of 384 and $348 \mathrm{~cm}$, respectively. The smallest total panicle lengths were recorded for Fern, Flam, and Aug, with measurements of 178, 167, and
$164 \mathrm{~cm}$, respectively. Rot and Sacc appeared in a middle position for this trait (Fig. 3).

For the size of the longest raceme, a variability of $9 \mathrm{~cm}$ (36\% of the mean) was recorded. Gol presented the largest size, with a measurement of $29 \mathrm{~cm}$. Regarding the longest raceme, the smallest size was recorded for Fern, with a measurement of $20 \mathrm{~cm}$. Male, Sacc, Flam, Rot, and Aug appeared to be in a middle position for this trait (Fig. 3).

A variability of 15 racemes ( $94 \%$ of the mean) was observed for the raceme number per panicle; Male presented the highest number, with 24 racemes. With 9 and 11 racemes, respectively, Flam and Aug had the lowest numbers of racemes. Gol, Rot, Fern, and Sacc appeared to be in a middle position for this trait (Fig. 3).

Rot had the highest floral density, with 5.4 flowers $/ \mathrm{cm}$. Flam and Sacc presented the lowest densities, with 4.2 and 3.7 flowers $/ \mathrm{cm}$, respectively. The other clones appeared to be in a middle position for this trait (Fig. 3).

Finally, for the total flower number per panicle, a variability of 903 flowers ( $83 \%$ of the mean) was observed among the clones studied. The clones Male, Rot, and Gol appeared to be the highest producers, with 1,619,1,417 and 1,414 flowers per panicle, respectively. Fern, Sacc, Aug, and Flam appeared to be the lowest producers, with 891, 833, 771 and 716 flowers per panicle, respectively (Fig. 3).

The Clones Showed Different Sensitivities to Environmental Conditions for Flowering and Panicle Architecture Traits

The clone $\times$ environmental condition interaction had a significant effect on all traits, except for the interval between the PE and the OF (Table 3).

For the panicle emergence and the onset of flowering, significant differences between the two temperatures, cool and warm, were detected for the clones Flam and Yaku (Table 4a). For these clones, the panicle emergence and the onset of flowering appeared to be delayed in warm condition when compared to cool condition (Table 4a). Significant differences between the two day lengths, short day length and natural day length, were observed for all the four clones tested: Flam, Male, Sacc, and Yaku (Table 4b). For these clones, the panicle emergence and the onset of flowering appeared to be delayed in natural day length condition when compared with short day length condition (Table 4b). The LSMEAN differences for the panicle emergence and the onset of flowering tended to be greater for day length factor (Table $4 \mathrm{~b}$ ) than for temperature factor (Table 4a). Moreover, for these two traits, day length factor seemed to affect more clones than temperature factor (Table $4 a, b$ ). It suggested that the day length factor was the most important environmental factor creating differential clone sensitivities for these two traits. Moreover, for the panicle emergence, the interaction between day length and temperature was significant for the 
Table 3 Analysis of variance of traits related to flowering and traits related to panicle architecture on the eight Miscanthus clones

Traits related to flowering (observed on four clones) Traits related to panicle architecture (observed on seven clones)

\begin{tabular}{|c|c|c|c|c|c|c|c|c|c|c|}
\hline Variable & & $\begin{array}{l}\text { Date of } \\
\text { panicle } \\
\text { emergence } \\
\text { dd }\end{array}$ & $\begin{array}{l}\text { Date of onset } \\
\text { of flowering } \\
\text { dd }\end{array}$ & $\begin{array}{l}\text { Interval } \\
\text { between PE } \\
\text { and OF } \\
\text { dd }\end{array}$ & & $\begin{array}{l}\text { Total } \\
\text { panicle } \\
\text { length } \\
\mathrm{cm}\end{array}$ & $\begin{array}{l}\text { Longest } \\
\text { panicle raceme } \\
\text { size } \\
\mathrm{cm}\end{array}$ & $\begin{array}{l}\text { Raceme } \\
\text { number per } \\
\text { panicle }\end{array}$ & $\begin{array}{l}\text { Floral density } \\
\text { per panicle } \\
\text { flower } \mathrm{cm}^{-1}\end{array}$ & $\begin{array}{l}\text { Total flower } \\
\text { number per } \\
\text { panicle }\end{array}$ \\
\hline Source of variation & $d f$ & $F$ & $F$ & $F$ & $d f$ & $F$ & $F$ & $F$ & $F$ & $F$ \\
\hline Clone & 3 & $34.5^{*}$ & $37.4^{*}$ & $6.0^{*}$ & 6 & $27.8^{*}$ & $25.6^{*}$ & $24.9 *$ & $18.2^{*}$ & $18.8^{*}$ \\
\hline Env. cond.* clone & 9 & $5.9 *$ & $5.6^{*}$ & $1.9 \mathrm{~ns}$ & 18 & $3.5^{*}$ & $2.9^{*}$ & $2.5^{*}$ & $4.7^{*}$ & $3.4^{*}$ \\
\hline Mean & & 1,464 & 1,531 & 54 & & 252 & 25 & 16 & 4.5 & 1,141 \\
\hline$R^{2}$ & & 0.82 & 0.85 & 0.62 & & 0.65 & 0.62 & 0.55 & 0.46 & 0.61 \\
\hline $\mathrm{CV}$ & & 5 & 4 & 33 & & 36 & 13 & 39 & 14 & 41 \\
\hline
\end{tabular}

Interval between PE and OF corresponded to interval between panicle emergence and onset of flowering

$C V$ coefficient of variation, $d d$ degree days, $d f$ degree of freedom, Env. cond. environmental condition, $F F$ value, $n s$ non significant at the 0.05 probability level

*Significant at the 0.05 probability level
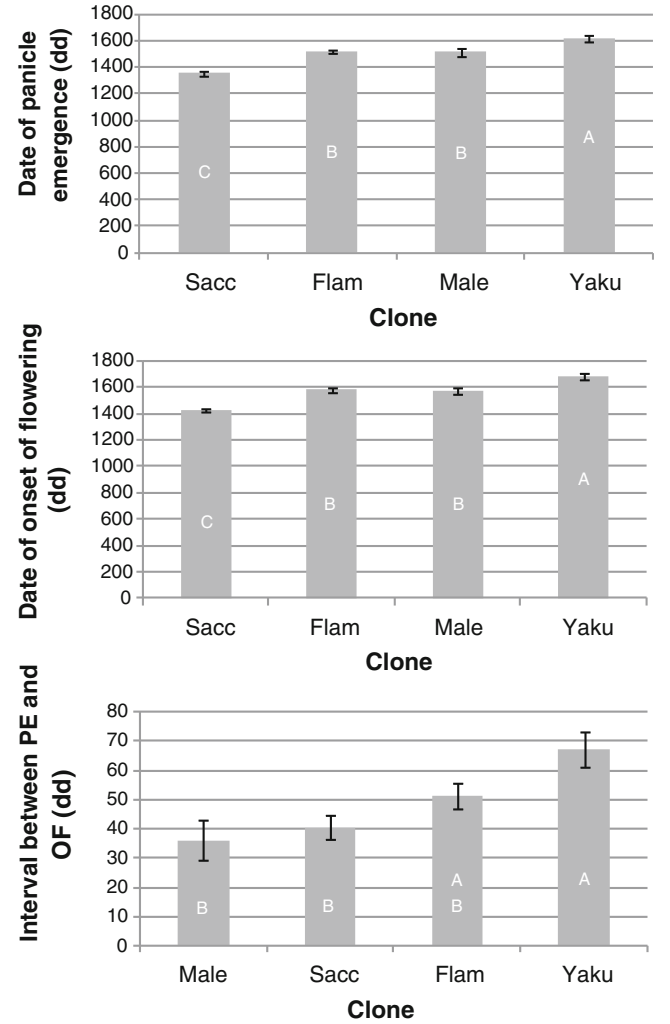

Fig. 2 Flowering traits as a function of Miscanthus clone. Values for each clone corresponded to LSMEANS across the four environmental conditions. Uppercase letters corresponded to significantly different groups determined using Bonferroni $t$ tests $(P \leq 0.05)$; errors bars corresponded to standard errors. $d d$ degree days, $O F$ onset of flowering, $P E$ panicle emergence clones Sacc and Yaku. For the onset of flowering, this interaction was significant only for the clone Yaku (Table 4c).

For the total panicle length, there were significant differences between the two temperature conditions, cool and warm, for all the clones tested except for Fern (Table 4a). The total panicle length appeared to decrease for the clone Sacc in warm condition when compared to cool condition, in contrast to the other clones for which a significant difference was highlighted (Table 4a). Significant differences between the two day lengths, short day length and natural day length, were also detected for the total panicle length but only for three clones: Fern, Male, and Rot (Table 4b). For these three clones, the total panicle length appeared to increase in natural day length when compared with short day length (Table $4 b$ ). The LSMEAN differences for the total panicle length seemed to be similar between temperature factor (Table 4a) and day length factor (Table 4b). It suggested that day length and temperature factors had similar effects on the differential clone sensitivity regarding the total panicle length. Nevertheless, temperature factor seemed to affect more clones than day length factor (Table 4a, b). The interaction between day length and temperature was significant for the clones Rot and Sacc (Table 4c).

For the longest panicle raceme size, significant differences were observed between the two temperature conditions for all the clones studied except for the clone Sacc (Table 4a). The size of the longest panicle raceme tended to increase in warm condition when compared to cool condition on the clones for which a significant difference was highlighted (Table 4a). Significant differences were also detected between the two 

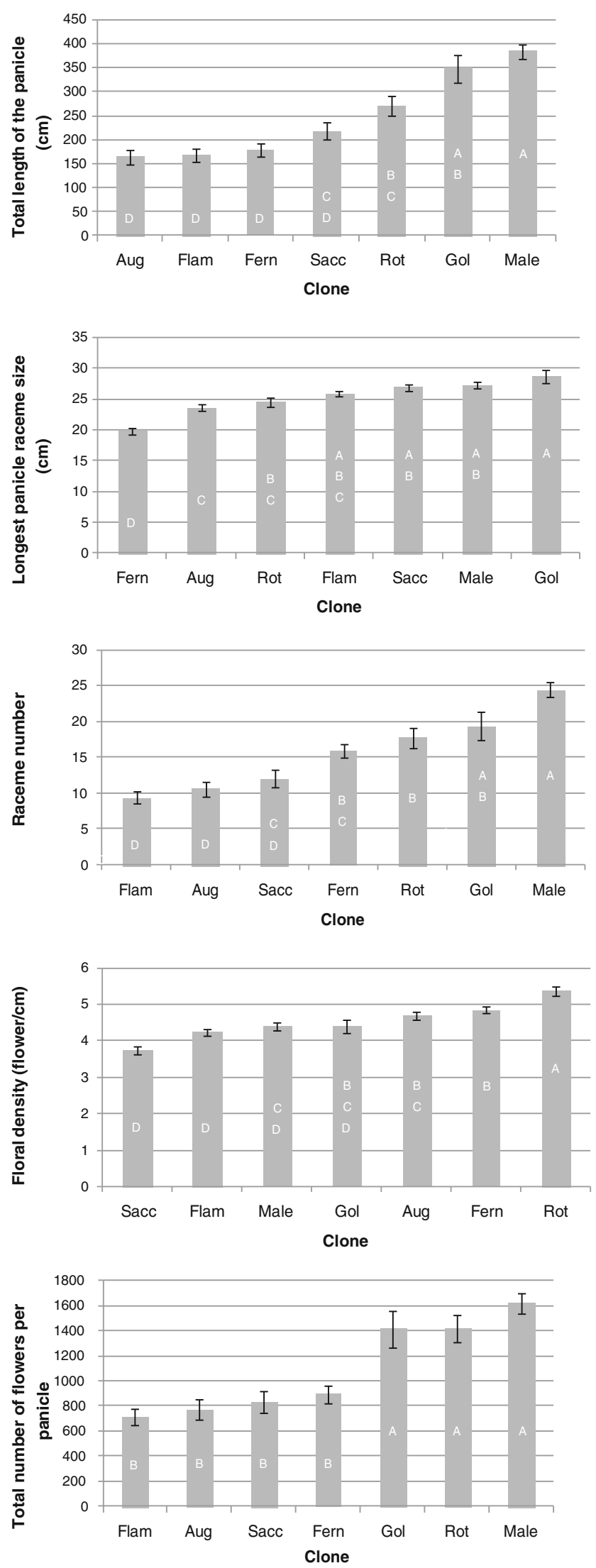

Fig. 3 Panicle architecture traits as a function of Miscanthus clone. Values for each clone corresponded to LSMEANS across the four environmental conditions. Uppercase letters corresponded to significantly different groups determined using Bonferroni $t$ tests $(P \leq 0.05)$; errors bars corresponded to standard errors

day lengths for all the clones studied except for Flam and Sacc (Table 4b). The longest panicle raceme size appeared to increase in natural day length when compared with short day length on the clones for which a significant difference was highlighted (Table 4b). The LSMEAN differences for the longest panicle raceme size seemed to be similar between temperature factor (Table 4a) and day length factor (Table 4b). It suggested that these two environmental factors had similar effects on the clone sensitivity for the longest panicle raceme size. The interaction between day length and temperature was significant for the clones Fern, Male, Rot, and Sacc (Table 4c).

For the raceme number per panicle, there were significant differences between the two temperature conditions for the clones Flam, Rot, and Sacc (Table 4a). Surprisingly, the raceme number appeared to decrease for the clone Sacc in warm condition when compared to cool condition, in contrast to the clones Flam and Rot (Table 4a). There were also significant differences between the two day lengths for the clones Fern, Male, and Rot (Table 4b). The raceme number appeared to increase in natural day length when compared with short day length on the clones for which a significant difference was highlighted (Table $4 \mathrm{~b}$ ). The LSMEAN difference for the raceme number per panicle tended to be greater for day length factor (Table $4 \mathrm{~b}$ ) than for temperature factor (Table 4a). It suggested that day length factor was the most important environmental factor creating differential clone sensitivities for the raceme number per panicle. In addition, both day length and temperature factors affected fewer clones for the raceme number per panicle than for the other variables. The interaction between day length and temperature was significant on this trait for the clone Rot (Table 4c).

For the floral density per panicle, significant differences between the two temperatures, cool and warm, were observed for the clones Aug and Fern (Table 4a). The floral density appeared to increase for the clone Fern in warm condition when compared to cool condition, in contrast to the clone Aug (Table 4a). Significant differences between the two day lengths, short day length and natural day length, were also observed for all the clones studied except for Male and Rot (Table 4b). Surprisingly, the floral density of Sacc appeared to increase in natural day length when compared to short day length, contrary to the other clones for which a significant difference was highlighted (Table $4 \mathrm{~b}$ ). The LSMEAN differences for the floral density per panicle seemed to be similar in absolute value between temperature factor (Table 4a) and day length factor (Table 4b). It suggested that these two environmental factors had similar effects on the differential clone 
Table 4 Differential environmental sensitivities of the eight Miscanthus clones given in the LSMEAN differences between (a) the two temperatures tested (cool vs. warm), (b) the two day lengths tested (short day length vs. natural day length), and (c) for the interaction between temperature and day length for each variable and for each clone separately

\begin{tabular}{|c|c|c|c|c|c|c|c|c|}
\hline \multirow[b]{2}{*}{ Clone } & \multirow[b]{2}{*}{$\begin{array}{l}\text { Variable } \\
\text { Unit }\end{array}$} & \multicolumn{2}{|c|}{$\begin{array}{l}\text { Traits related to flowering } \\
\text { (observed on four clones) }\end{array}$} & \multicolumn{3}{|c|}{$\begin{array}{l}\text { Traits related to panicle architecture (observed } \\
\text { on seven clones) }\end{array}$} & \multirow[b]{2}{*}{$\begin{array}{l}\text { Floral density } \\
\text { per panicle } \\
\text { flower } \mathrm{cm}^{-1}\end{array}$} & \multirow[b]{2}{*}{$\begin{array}{l}\text { Total flower number } \\
\text { per panicle }\end{array}$} \\
\hline & & $\begin{array}{l}\text { Date of panicle } \\
\text { emergence } \\
\text { dd }\end{array}$ & $\begin{array}{l}\text { Date of onset of } \\
\text { flowering } \\
\text { dd }\end{array}$ & $\begin{array}{l}\text { Total panicle } \\
\text { length } \\
\mathrm{cm}\end{array}$ & $\begin{array}{l}\text { Longest panicle } \\
\text { raceme size } \\
\mathrm{cm}\end{array}$ & $\begin{array}{l}\text { Raceme number } \\
\text { per panicle }\end{array}$ & & \\
\hline
\end{tabular}

Differences between the two temperatures: cool - warm $=$ Env. cond. $(1+3)-$ Env. cond. $(2+4)$

\begin{tabular}{|c|c|c|c|c|c|c|c|}
\hline Aug & & & $-65^{*}$ & $-5^{*}$ & ns & $0.5^{*}$ & $-205^{*}$ \\
\hline Fern & & & ns & $-3^{*}$ & ns & $-0.4^{*}$ & ns \\
\hline Flam & $-247^{*}$ & $-174^{*}$ & $-84^{*}$ & $-4^{*}$ & $-5^{*}$ & ns & $-343^{*}$ \\
\hline Gol & & & $-117^{*}$ & $-3^{*}$ & ns & ns & $-920^{*}$ \\
\hline Male & ns & ns & $-141^{*}$ & $-4^{*}$ & ns & ns & $-787^{*}$ \\
\hline Rot & & & $-133^{*}$ & $-4^{*}$ & $-6^{*}$ & ns & $-805^{*}$ \\
\hline Sacc & ns & $\mathrm{ns}$ & $57^{*}$ & ns & $4^{*}$ & ns & ns \\
\hline Yaku & $-148^{*}$ & $-90^{*}$ & & & & & \\
\hline LSMEAN difference & -124 & -72 & -74 & -3 & -2 & -0.1 & -429 \\
\hline Standard error & 45 & 32 & 26 & 1 & 2 & 0.2 & 126 \\
\hline
\end{tabular}

Differences between the two day lengths: SD - ND = Env. cond. $(1+2)-$ Env. cond. $(3+4)$

\begin{tabular}{|c|c|c|c|c|c|c|c|}
\hline Aug & & & ns & $-4^{*}$ & ns & $0.8^{*}$ & ns \\
\hline Fern & & & $-57^{*}$ & $-2^{*}$ & $-4^{*}$ & $0.3^{*}$ & $-270^{*}$ \\
\hline Flam & $-190^{*}$ & $-159^{*}$ & ns & ns & ns & $0.4^{*}$ & ns \\
\hline Gol & & & ns & $-4^{*}$ & ns & $0.7^{*}$ & ns \\
\hline Male & $-240^{*}$ & $-171^{*}$ & $-200^{*}$ & $-4^{*}$ & $-13^{*}$ & ns & $-820^{*}$ \\
\hline Rot & & & $-128^{*}$ & $-5^{*}$ & $-4^{*}$ & ns & $-579^{*}$ \\
\hline Sacc & $-190^{*}$ & $-97^{*}$ & ns & ns & ns & $-0.9^{*}$ & ns \\
\hline Yaku & $-187^{*}$ & $-175^{*}$ & & & & & \\
\hline LSMEAN difference & -202 & -150 & -74 & -3 & -4 & 0.1 & -291 \\
\hline Standard error & 41 & 27 & 28 & 1 & 2 & 0.2 & 142 \\
\hline
\end{tabular}

$\mathrm{c}$ Interaction between day length and temperature: day length * temperature = Env. cond. $(1+4)-$ Env. cond. $(2+3)$

\begin{tabular}{|c|c|c|c|c|c|c|c|}
\hline Aug & & & ns & ns & ns & ns & $\mathrm{ns}$ \\
\hline Fern & & & ns & $2^{*}$ & ns & ns & $\mathrm{ns}$ \\
\hline Flam & ns & ns & ns & ns & ns & $-0.5^{*}$ & ns \\
\hline Gol & & & $\mathrm{ns}$ & ns & ns & $\mathrm{ns}$ & $\mathrm{ns}$ \\
\hline Male & ns & ns & ns & $2^{*}$ & ns & ns & $493^{*}$ \\
\hline Rot & & & $146^{*}$ & $5^{*}$ & $4^{*}$ & ns & $861^{*}$ \\
\hline Sacc & $164^{*}$ & $\mathrm{~ns}$ & $89^{*}$ & $7^{*}$ & ns & $0.6^{*}$ & $411^{*}$ \\
\hline Yaku & $-130^{*}$ & $-162^{*}$ & & & & & \\
\hline LSMEAN difference & 42 & -19 & 52 & 3 & 0 & 0.0 & 246 \\
\hline Standard error & 50 & 35 & 31 & 1 & 2 & 0.2 & 151 \\
\hline
\end{tabular}

Differences were not reported for the interval between panicle emergence and onset of flowering as the clone $\times$ environmental condition interaction was not significant on this trait (see Table 3). Details about each of the four environmental conditions tested (1, 2, 3, and 4) were given in Table 2

$d d$ degree days, Env. cond. environmental conditions, LSMEAN least-squares mean, $N D$ natural day length, $S D$ short day length, $n s$ non significant at the 0.05 probability level

* Significant at the 0.05 probability level 
sensitivity regarding the floral density. Nevertheless, day length factor seemed to affect more clones than temperature factor (Table 4a, b). The interaction between day length and temperature was significant on this trait for the clones Flam and Sacc (Table 4c).

For the total flower number per panicle, significant differences between the two temperature conditions were observed for all the clones tested except for the clones Fern and Sacc (Table 4a). The total flower number seemed to increase in warm condition when compared with the cool condition on the clones for which a significant difference was highlighted (Table 4a). Significant differences were also highlighted between the two day lengths, short day length and natural day length, for the clones Fern, Male, and Rot (Table 4b). The total number of flowers per panicle tended to increase in natural day length when compared to short day length on the clones for which a significant difference was highlighted (Table 4b). For this trait, the LSMEAN difference seemed to be greater for temperature factor (Table 4a) than for day length factor (Table $4 b$ ). Moreover, temperature factor seemed to affect more clones than day length factor (Table 4a, b). It suggested that temperature was the most important environmental factor creating differential clone sensitivities for the total flower number per panicle. The interaction between day length and temperature was significant for the clones Male, Rot, and Sacc (Table 4c).

In summary, this study highlighted a broad variability in the flowering and panicle architecture traits of the eight Miscanthus clones. In addition to the clone influence, the eight clones studied were sensitive to environmental conditions for the flowering and panicle architecture traits except for the interval between the PE and the OF. Comparing the day length and temperature factors, the day length appeared to be the most important environmental factor creating differential clone sensitivities for the panicle emergence and the onset of flowering. In contrast, the temperature seemed to be the most important environmental factor creating differential clone sensitivities for the total flower number per panicle. Moreover, for several of the panicle architecture traits, the behavior of the clone Sacc was in contrast with that of the other clones.

\section{Discussion}

The variability in flowering and panicle architecture traits in Miscanthus must be characterized to provide guidelines to breeders (synchronization of flowering, panicle architecture, number of flowers, etc.).

Below, we first discuss two points directly related to our hypotheses:

- the genotypic variability in traits related to flowering and panicle architecture; and
- the sensitivity of different genotypes to environmental conditions and, more particularly, to day length and temperature variations.

In addition, our study also assumes that the environmental conditions may influence flowering and panicle architecture traits. We therefore finally discuss the third following point:

- the influence of the environmental conditions on flowering and panicle traits.

As only a few studies have focused on the floral phenology of Miscanthus, we have broadened the discussion to crops that are taxonomically related to Miscanthus, more particularly to sorghum, maize, and sugarcane.

Genotypic Variability in Traits Related to Flowering and Panicle Architecture

Our prediction that there would be clonal variability in traits related to flowering and panicle architecture is supported in the studies discussed below.

Jensen et al. [21, 22] observed variability in the date of panicle emergence and in the flowering time among 244 genotypes of M. sinensis, M. sacchariflorus, and interspecific hybrids. Clifton-Brown et al. [4] studied 248 Miscanthus genotypes and concluded that there was a considerable genotypic variability in the Miscanthus flowering time. The significant differences in flowering time highlighted in our study among only four clones reinforced the conclusion of CliftonBrown et al. [4]. The variability among Miscanthus clones observed during our study in the date of panicle emergence, the date of flowering onset, and the interval between the panicle emergence and the onset of flowering reinforced the existence of considerable genotype variability.

No study in Miscanthus reported traits related to panicle architecture. However, a genotypic variability in some of these traits has been observed in crops closely related to Miscanthus. Cisneros-Lopez et al. [32] reported that, in sorghum, the rachis length of the panicle, which corresponds to the size of the longest raceme measured in our study, varied significantly, from 20 to $26 \mathrm{~cm}$, as a function of the Sorghum lines considered. The genotypic variability observed for the rachis length in sorghum is similar to the differences highlighted among the Miscanthus clones we studied. In terms of raceme number, Cisneros-Lopez et al. [32] and Upadyayula et al. [33] showed that the primary branch number per panicle is different among Sorghum lines. The authors also showed that this trait is different among maize parents. Upadyayula et al. [33] also mentioned significant differences between two maize parents in two traits similar to the floral density: the number of spikelet pairs on the top $4 \mathrm{~cm}$ of the central spike and the number of spikelet pairs on the top $6 \mathrm{~cm}$ of the lowermost primary branch. Cisneros-Lopez et al. [32] 
highlighted a genotypic effect on the number of fertile flowers per panicle, which is a trait similar to the flower number per panicle observed during our study.

The observations cited above are in agreement with our results showing that flowering and panicle architecture traits vary with Miscanthus clones. Therefore, this clonal variability should be useful for developing efficient breeding programs in Miscanthus .

The Sensitivity of Different Genotypes to Environmental Conditions and More Particularly to Day Length and Temperature Variations

We suggested that the sensitivity of genotypes to environmental conditions, such as day length and temperature variations, could be different for flowering and panicle architecture traits. Our suggestion is supported in the following studies.

Some studies showed an interaction between the genotype and the day length for traits related to flowering; Machado et al. [25], Berding et al. [10, 11, 13], and Rizk et al. [26] demonstrated that sugarcane varieties varied considerably in terms of their flowering response to photoperiod variations. These findings reinforce our results showing that the differential sensitivity of Miscanthus clones to environmental conditions was mostly due to day length when compared with temperature for flowering traits.

Some studies mentioned different genotype sensitivities towards temperature variations for flowering and panicle architecture traits. In sugarcane, Berding [9] showed an interaction between sugarcane varieties and temperature for flowering time. This observation is in agreement with our results showing that some Miscanthus clones were sensitive to temperature variation for the onset of flowering. In sorghum, Cisneros-Lopez et al. [32] stated that the year $\times$ genotype interaction was not significant for the panicle rachis length or the total number of flowers per panicle. As the authors associated the year effect with a temperature effect, this result suggested that the temperature $\times$ genotype interaction was not significant for these two traits in sorghum. These findings are in disagreement with our results; we found that some Miscanthus clones were sensitive to temperature variations for the raceme number per panicle and the total flower number per panicle suggesting a significant temperature $x$ genotype interaction for these two traits. We also showed that the differential clone sensitivity regarding the total number of flowers per panicle was mostly due to the temperature factor.

Finally, the results cited above demonstrate that the behavior of genotypes in response to environmental variations, such as day length and temperature variations varies with the species with regards to flowering and panicle architecture traits. These observations are consistent with our results showing differential Miscanthus clone sensitivities for flowering and panicle architecture traits according to day length and temperature conditions.

Variations in Flowering and Panicle Architecture as a Function of Environmental Condition Mainly Explained by Day Length and Temperature

Our suggestion that flowering and panicle architecture traits can be influenced by environmental conditions such as day length and temperature is supported in the following studies.

In sugarcane, Nuss [8] showed that the time of anthesis is affected by the rate of decline in day length. Moore et al. [7] also showed that the first inflorescence emerged 1 week later for treated plants (light treatment) than for untreated control plants (a short day length) in Hawaii. In Brasil, Machado et al. [25] found that the onset of flowering varied as a function of the lighting treatment. In Miscanthus sacchariflorus, flowering under static long days was delayed by an average of 61 days compared to shorter photoperiods [22]. Furthermore, Jensen et al. [22] showed that the flowering induction of Miscanthus sacchariflorus demonstrated a quantitative response to day length. These observations were consistent with our hypothesis that flowering traits were influenced by environmental conditions in Miscanthus, and more particularly by day length and temperature.

Previous studies also mention a significant temperature effect on flowering and panicle architecture traits. One study by Jensen et al. [21] reported a year effect on the flowering time of Miscanthus species observed in a UK field trial, suggesting an effect of climatic conditions, such as temperature and rainfall, on flowering time. Nuss [8] and Berding [9] observed that the flowering time was significantly earlier during higher night temperatures than during lower night temperatures in several sugarcane varieties. Cisneros-Lopez et al. [32] mentioned an effect of the temperature when studying a year effect on the rachis length of the panicle, a trait corresponding to the size of the longest raceme measured during our study, and on the total number of flowers per panicle in several Sorghum lines.

These observations confirm that variability in flowering and panicle architecture traits can be explained by environmental conditions, such as day length and temperature, and this is consistent with our prediction.

\section{Conclusion}

The findings of the present study demonstrate the genotype variability in Miscanthus flowering and panicle architecture. Of the eight clones observed, Sacc appeared to have the earliest panicle emergence and flowering time when compared with Yaku, which had the latest. Male appeared to have the longest total panicle length, the highest raceme number per 
panicle, and the highest total flower number per panicle. The present study revealed that the eight Miscanthus clones studied displayed different sensitivities to environmental conditions and more particularly to day length and temperature variations. The behavior of Sacc was in contrast with that of the other clones. This difference was expected as the clone Sacc belongs to a different Miscanthus species. The knowledge on these different clone sensitivities toward environmental conditions is useful for optimizing the crossings between parents.

As the two Miscanthus species studied here displayed different sensitivities to environmental conditions regarding the flowering and panicle architecture traits, more investigation on more species is still needed on this topic to monitor the environmental conditions required to maximize the number of successful crossings for the development of efficient breeding programs in Miscanthus.

Acknowledgments The authors would like to acknowledge the support of the Picardie Regional Council via the PEL project. Our special thanks go to Marie-Chantal Mansard and the staff working in the INRA greenhouses in Estrées-Mons for their practical advice and technical assistance, which enabled the success of the experiments. We also thank Alexandra Hocdé and Ghislaine Lauwerier for their assistance with the experiments during their professional training. We thank Professor André Gallais and all the reviewers for their valuable comments. We particularly thank Danièle Roques, from CIRAD in Guadeloupe, and Nils Berding, from BSES Meringa in Australia, for their input on sugarcane.

Open Access This article is distributed under the terms of the Creative Commons Attribution License which permits any use, distribution, and reproduction in any medium, provided the original author(s) and the source are credited.

\section{References}

1. Jones MB, Walsh M (2001) Miscanthus for energy and fibre. James and James Publishers, London

2. Lewandowski I, Clifton-Brown JC, Scurlock JMO, Huisman W (2000) Miscanthus: European experience with a novel energy crop. Biomass Bioenergy 19:209-277

3. Angelini LG, Geccarini L, Nassi o Di Nasso N, Bonari E (2009) Comparison of Arundo donax L. and Miscanthus $\times$ giganteus in a long-term field experiment in Central Italy: Analysis of productive characteristics and energy balance. Biomass Bioenergy 33:635-643

4. Clifton-Brown JC, Chiang YC, Hodkinson TR (2008) Miscanthus: genetic resources and breeding potential to enhance bioenergy production. In: Vermerris W (ed) Genetic improvement of bioenergy crops. Springer, Berlin, pp 273-294

5. Greef JM, Deuter M (1993) Syntaxonomy of Miscanthus $\times$ giganteus Greef-Et-Deu. Angew Bot 67(3-4):87-90

6. Clements HF (1968) Lengthening versus shortening dark periods and blossoming in sugar cane as affected by temperature. Plant Physiol 43:57-60

7. Moore PH, Heinz DJ (1972) Photoperiodic delay and extension of the flowering season of early flowering Saccharum spontaneum hybrids. Hawaii Planter's Rec 58(13):165-172

8. Nuss KJ (1980) Effects of photoperiod and temperature on initiation and development of flowers in sugarcane. Proc Int Soc Sugar Cane Technol 17:486-493
9. Berding N (1981) Improved flowering and pollen fertility in sugarcane under increased night temperatures. Crop Sci 21: $863-867$

10. Berding N, Moore PH (1996) Towards optimized induction of flowering in sugarcane. In: Wilson JR et al (eds) Sugarcane: research towards efficient and sustainable production. CSIRO Division of Tropical Crops and Pastures, Brisbane, pp 44-46

11. Berding N, Moore PH (2001) Advancing from opportunistic sexual recombination in sugarcane: lessons from tropical photoperiodic research. Proc Int Soc Sugar Cane Technol 24:482-487

12. Berding N, Pendrigh RS, Dunne V (2007) Can flowering in sugarcane be optimised by use of differential declinations for the initiation and development phases? XXVI Congr, Int Soc Sugar Cane Technol 29 July - 02 August, 2007, ICC, Durban, South Africa

13. Berding N, Pendrigh RS, Dunne V (2010) Pursuing higher efficacy for managed photoperiodic initiation of sugarcane flowering in the tropics. Proc Aust Soc Sugar Cane Technol 32:234-250

14. Yin X, Kropff MJ, Goudriaan J (1996) Differential effects of day and night temperature on development to flowering in rice. Ann Bot 77: 203-213

15. Yin X, Kropff MJ, Ellis RH (1996) Rice flowering in response to diurnal temperature amplitude. Field Crop Res 48:1-9

16. Yin X, Kropff MJ (1998) The effect of photoperiod on interval between panicle initiation and flowering in rice. Field Crops Res 57(3):301-307

17. Yanase M, Tarumoto I, Kasuga S (2008) Effects of day length and night temperature on the flowering of sorghum varieties with a dominant thermosensitivity gene. Japanese Soc Grassland Sci 54: $57-61$

18. Gosnell JM (1973) Some factors affecting flowering in sugarcane. Proc S Afr Sugar Technol Ass 47:144-147

19. Lewandowski (2000) European Miscanthus Improvement (FAIR3 CT 96 1392) Broadening the genetic base, testing genotypes and development of breeding methods. Final Report for the period from 01.01 .97 to 28.02 .00

20. Clifton-Brown JC, Lewandowski L, Andersson B, Basch G, Christian DG, Kjeldsen JB, Jørgensen U, Mortensen JV, Riche AB, Schwarz KU, Tayebi K, Teixeira F (2001) Performance of 15 Miscanthus clones at five sites in Europe. Agron J 93(5):1013-1019

21. Jensen E, Farrar K, Thomas-Jones S, Hastings A, Donnison I, Clifton-Brown J (2011) Characterization of flowering time diversity in Miscanthus species. Glob Chang Biol Bioenergy 3(5):387-400

22. Jensen E, Robson P, Norris J, Cookson A, Farrar K, Donnison I, Clifton-Brown J (2013) Flowering induction in the bioenergy grass Miscanthus is a quantitative short-day response, whilst delayed flowering under long days increases biomass accumulation. J Exp Bot 64(2):541-552

23. Gauder M, Graeff-Hönninger S, Lewandowski I, Claupein W (2012) Long-term yield and performance of 15 different Miscanthus genotypes in southwest Germany. Ann Appl Biol. doi:10.1111/j.17447348.2011.00526.x

24. Nuss KJ (1982) Flowering of sugarcane in a photoperiod house from 1971 to 1981. Proc S Afr Sugar Technol Ass 56:140-142

25. Machado GR Jr, de Oliveira JA, Walker I (1990) Photoperiod control of flowering at Camamu, Brazil. Sugar Cane 5:1-6

26. Rizk TY, Khalil HA, Nosaer HA (2007) Effect of two-photoperiod regimes on flower induction of five non flowering sugar cane varieties. Proc Afr Crop Sci Conf 8:155-159

27. Jezowski S, Glowacka K, Kaczmarek Z (2011) Variation on biomass yield and morphological traits of energy grasses from the genus Miscanthus during the first years of crop establishment. Biomass Bioenergy 35:814-821

28. Jakob K, Zhou FS, Paterson A (2009) Genetic improvement of C4 grasses as cellulosic biofuel feedstocks. In Vitro Cell Dev Biol-Plant 45(3):291-305 
29. Zub HW, Arnoult S, Brancourt-Hulmel M (2011) Key traits for biomass production identified in different Miscanthus species at two harvest dates. Biomass Bioenergy 35:637-651

30. Demay C, Cadoux S, Boizard H, Dürr C (2010) Effects of temperature and water potential on the emergence of Miscanthus and the germination of switchgrass. May 03-07, 2010, 18th Eur Biomass Conf, Lyon, France

31. SAS Institute Inc (1999) SAS/STAT User's guide. Version 8, SAS Institute Inc, Cary, $\mathrm{NC}$
32. Cisneros-Lopez ME, Mendoza-Onofre LE, Zavaleta-Mancera HA, Gonzales-Hernandez VA, Cordova-Tellez L, Hernandez-Martinez M, Mora-Aguilera G (2009) Floral traits and seed production of sorghum A-, B- and R-lines under chilling field temperatures. J Agron Crop Sci 195(6):464-471

33. Upadyayula N, Da Silva HS, Bohn MO, Rocheford TR (2006) Genetic and QTL analysis of maize tassel and ear inflorescence architecture. Theor Appl Genet 112(4):592-606 